\title{
A Critical Approach to Acculturation Models
}

\author{
Bei JU \\ International Business Faculty \\ Beijing Normal University Zhuhai Campus \\ Zhuhai, People's Republic of China
}

\begin{abstract}
This paper attempts to critically analyze the two prominent acculturation models, namely, the unidirectional model and the bidirectional model. Then the communication acculturation model is introduced to examine acculturation based on the levels of individuals, interactions between individuals and groups, and their interactivity within home and host culture. Therefore, it is suggested that the studies will be more practical when setting acculturation model within the specific social context to describe the diverse-level changes occurring in the process of acculturation.
\end{abstract}

Keywords- acculturation, unidirectional model, bidirectional model, communication model

\section{INTRODUCTION}

In an increasingly plural and mobile world, people from diverse cultures transcend national boundaries, coming into the dynamic contact with each other. Over this process, changes of individuals, groups and society have taken place reflecting the active interactions between home culture and host culture. The term "acculturation" is widely used to describe these changes and acculturation models attempt to reveal the underlying reasons for their occurrence. However, the meanings of acculturation are confused which results in numerous theories and models of acculturation, which lack of unity and consistency. Therefore, only three models: the unidirectional model, the bidirectional model and the communication acculturation model have been chosen to be critically examined due to their efficiency and representativeness.

\section{THE CONCEPT OF ACCULTURATION}

According to Powell, the first person to use the term "acculturation" in 1880, acculturation refers to psychological changes induced by cross-cultural imitation (Sam \& Berry, 2006, p.13). It is not uncommon that social scientists including psychologists, sociologists, and anthropologists adopt different terms to interpret the concept of acculturation. The widely accepted meaning was defined by Redfield, Linton and Herskovits (1936, p. 149) as "acculturation comprehends those phenomena which result when groups of individuals having different cultures come into continuous first-hand contact, with subsequent changes in the original culture patterns of either of both group".

Generally, anthropologists and sociologists prefer to use the term "assimilation" to emphasize the features of groups and societies following contact with the host culture, while psychologists tend to use the term "acculturation" to indicate more personal characteristics change in the process of acculturation. Organista, Marin \& Chun (2010, p. 103) further pointed out that variations in terminology and emphasis have undermined the advancement of the field and of our understanding of the acculturation process when there is little cross-fertilization between fields. Consequently, the acculturation models such as directionality, ethno genesis, biculturalism, enculturation and bidirectionality, vary with diverse meanings of acculturation and interests of researchers.

\section{UNIDIRECTIONAL MODEL}

Driven by interests to explore how the individuals adapt themselves to the new dominant culture, the two most popular acculturation models are the unidirectional and the bidirectional model.

In the unidirectional model, acculturation is understood as synonym of assimilation. Gordon (1964) proposed an assimilation model to describe the immigrants' cultural changes during the gradual process of adaptation. In his theory, the process of adaptation is a continuum where one pole is the immigrant home culture and the other is the host culture which can be adopted only at the cost of discarding the cultural heritage. Therefore, the unidirectional model is featured as linear, straight-line. In terms of direction, the unidirectional model is not multidirectional. Proponents (Gans, 1979; Taylor, 1991) argued that assimilation does occur in multiple layers like economy, language and legislation. No matter unidirectional model is thought to be unipolar or of stage-like nature, the biggest weakness of unidirectional model is that this model ignores the culture of immigrants, and the influences of immigrants on the dominant culture. In other words, the unidirectional model completely separates the home and dominant cultures and only focuses on the outcome of the acculturation process. This notion is reflected in the commonly used phrase "melting pot", leaving no room for the existence of both home and host cultures. 


\section{BIDIRECTIONAL MODEL}

Limitations of unidirectional model contributed to the development of bidirectional model. Berry (1974, 1980) proposed that home and host cultures could be seen as independent dimensions rather than the two extremes of a linear continuum. More specifically, acculturation entails two related elements: maintenance of the home culture and adherence to the host culture. From the perspective of social psychology, immigrants living in the host culture will consider two questions: the immigrants' heritage culture should be retained or discarded; their relations with the host culture should be sought or avoided. Based upon the answers to these two questions, four prominent acculturation strategies: assimilation, separation, integration and marginalization are formed to help individuals when adapting into a new host culture (Berry, 1997). This framework was further developed by researchers (Ward et al., 2001; Safdar, Lay, \& Struthers, 2003; Rasmi, Safdar, \& Lewis, 2009) who also explored the characteristics of individuals and larger groups, and stressors as predictor variables. Even if the bidirectional model recognizes the existence of both home and host culture, it fails to explore how the dominant groups affect the immigrant groups, but only focuses on how immigrants adapt themselves into the host culture in a one way process. In this sense, it could be said that these two models of acculturation would be described as insufficient due to their incompleteness of interdependence between home and host culture.

In response to the perceived need to identify the mutual influences of home culture and host culture, Bourhis, Moise, Perrault \& Senecal, (1997) initiated the interactive acculturation model. This model did emphasize on what the dominant culture think the immigrants should do, but it did not ask how exactly the home culture affect the dominant one. Overall, both unidirectional and bidirectional models mainly examine how immigrants acculturate into the dominant culture and there is no single best acculturation model. Flannery, Reise, \& Yu (2001) recommended that the selected model should best match the social scientists' research topic and their population. For instance, the unidirectional model is an economical and proxy measure of acculturation that involve generational status, while the bidirectional model is for full theoretical investigation of acculturation.

\section{COMMUNICATION ACCULTURATION MODEL}

Most studies of acculturation are conducted from the perspectives of psychology and sociology. In my view, acculturation is like a learner learning how to swim. The learner should jump into the water to experience and practice. If the individuals do not possess communication competence, how can they adapt to the host culture which has its own norms and practice.

Berlo (1960, p.24) stated the features of communication as a process, "It is not static, at rest. It is moving. The ingredients within a process interact; each affects all of the others". This dynamic concept broadens the unidirectional model which only emphasizes the final static outcome of acculturation. Kim (1978) sustained that the process of acculturation should be redefined as the process of cognitive, attitudinal and behavioral adaptation to the new cultural system, rather than as the process of adopting the cultural values of a new society. This process is conceptualized as a communication process. Apart from the focus on the host culture from the perspective of immigrants' cognition and attitudes, the behavioral level of communication includes the immigrants' adoption of communication channels of the host culture and home culture as well. On the other hand, the communication model tries to examine the levels of attitude, cognitive and behavior, not limited to immigrants' attitudes towards the host and home culture.

Based on her research in 1978, $\operatorname{Kim}(1979,1982)$ proposed a systematic model of communicationacculturation. This model identifies four interrelated subsystems including personal/intrapersonal communication, interpersonal communication, mass media behaviors and communication environment. In this model, acculturation is interpreted as an interactive, dynamic and continuous process and integrates the individuals' personal awareness, the interaction between immigrants and local community, and the influences of host culture.Therefore, the home environment as well as the host environment would influence the communication-acculturation patterns of immigrants. To illustrate this point, the interpersonal communication and communication traits are examined to reveal how the interactions between home and host culture affect the immigrants' communication pattern (Rhee, Chang, \& Rhee, 2003; Chia-Fang, 2010).This idea effectively reveals the weakness of unidirectional and bidirectional models. These two models fail to notice the influence of both home and host culture on acculturation.

Furthermore, Kim (2003) developed communicationacculturation into an integrated theory of communication and cross-cultural adaptation which attempts to emphasize the psychological and ideological characteristics of individuals and groups over the length of time in both home and host cultures. It is a fact that this conceptualization is formed on the basis of a broad view of acculturation, representing the complicated and dynamic features of acculturation.

\section{RECOMMENDATIONS}

Generally speaking, the acculturation models are basically conceptualized on these three levels including individuals, interactions between individuals and groups, and their interaction with social and cultural factors. This trend gradually broadens the acculturation model into the circles but not only the straight-line continuum.

Acculturation, is an unavoidable phenomenon in social and cultural development. Although acculturation models are thought to be successful in revealing cognitive, attitudinal, behavioral, psychological, communication and cultural representation changes (language, clothing, values), the core of "acculturation" lies in the changes of "culture". However, globalization is incrementally changing the cultural boundaries among nations, some of them even becoming blurred. Under this circumstance, culture diversity is not easy for researchers to define and identity. Therefore, it is 
suggested that the objectivistic approach, to explain and predict the acculturation process should be combined with the subjectivistic approach, to describe the actual changes in the specific process of acculturation. In other words, the acculturation models set in the specific social contexts such as family, ethnic group, workplace will be more appropriate and feasible when researchers are observing the specific changes occurred.

\section{CONCLUSIONS}

To sum up, if the acculturation model only targets at explaining the generalized reasons for the acculturation based on its particularity, this model would not be effectively applicable in the current world of multi-cultures. Appropriately, more attention on how the social environment of politics, economy and culture influences acculturation will be helpful for discovering the issues happening at different levels. In this way, the acculturation model could be proposed as the exploration of integrated personal, communication and cultural changes of individuals reflected in the specific social context when individuals coming from the home culture interact with the dominant culture.

\section{References}

[1] Berlo, D.K. (1960). Communication: An introduction to theory and practice. New York: Holt, Rinehart \& Winston.

[2] Berry, J.M. (1974). Psychological aspects of culture pluralism. Cultural Learning, 2, 17-22.

[3] Berry, J.M. (1980). Acculturation as varieties of adaptation. In A.M. Padilla (Ed.), Acculturation: Theory, models and some new findings (pp.9-25). Boulder, CO: Westview.

[4] Berry, J.M. (1997). Immigration, acculturation, and adaptation. Applied Psychology: An International Review. 46 (1), 5-33.

[5] Bourhis, R.Y., Moise, L. C., Perrault, S. \&Senecal, S. (1997). Towards an interactive acculturation model: A social psychological approach. International Journal of Psychology, 32 (6), 369-386.

[6] Chia-Fang, H. (2010). Acculturation and communication Traits: A study of cross-cultural adaptation among Chinese in America. National Communication Association. 77 (3), 414-425.

[7] Flannery, W.P., Reise, S.P., \& Yu, J. (2001). An empirical comparison of acculturation models. Personality and Social Psychology Bulletin, 27, 1035-1045.
[8] Gans, H. (1979). Symbolic ethnicity: The future of ethnic groups and culture in American. Ethnic and Racial Studies, 2, 1-20.

[9] Gordon, M. (1964). Assimilation in American Life. New York: Oxford University Press.

[10] Kim, Y.Y. (1978). A Communication approach to the acculturation process: A study of Korean immigrants in Chicago, International Journal of Intercultural Relations/Summer, 197-224.

[11] Kim, Y.Y. (1979). Toward an interactive theory of communicationacculturation. In D. Nimmo (Ed.), Communication Yearbook (Vol. 3). New Brunswick, NJ: Transaction, 435-453.

[12] Kim, Y.Y. (1982). Communication and acculturation. In L.A. Samovar \& R.E. Porter (Eds.), Intercultural Communications: A Reader. Belmont, CA: Wadsworth.

[13] Kim, Y.Y. (2003). Becoming Intercultural: An integrative theory of communication and cross-cultural adaptation. Thousand Oaks, CA: Sage.

[14] Organista, P. B., Marin, G. \& Chun, K. M. (2010).The Psychology of Ethic Groups in the United States. California: SAGE Publications.

[15] Rasmi, S., Safdar, S., \& Lewis, J.R. (2009). A longitudinal examination of the MIDA model with international students. In A. Chybicka, S. Safdar, \& A. Kwiatkowska. (Eds.), Cultural and gender an intimate relations. Gdansk, Poland: Gdanskie Wydawnictwo Psychologiczne.

[16] Redfield,R., Linton, R. \& Herskovits, M.J. (1936). Memorandum for the study of Acculturation. American Anthropologist, 38(1). 149-152.

[17] Rhee, S., Chang, J. \& Rhee, J. (2003). Acculturation, communication patterns, and self-esteem among Asian and Caucasian American adolescents. Adolescence, 38 (152). 749-768.

[18] Safdar, S., Lay, C., \& Struthers, W. (2003). The process of acculturation and basic goals: Testing a multidimensional individual difference acculturation model with Iranian immigrant in Canada. Applied Psychology, 52,555-579.

[19] Sam, D.L. \& Berry, J. W. (2006). The Cambridge Handbook of Acculturation Psychology. Cambridge: Cambridge University Press.

[20] Taylor, D.M. (1991). The social psychology of racial and cultural diversity: Issues of assimilation and multiculturalism. In A.G. Reynolds (Ed.) Bilingualism, multiculturalism, and second language learning (pp. 1-19). Hillsdale, NJ: Lawrence Erlbaum.

[21] Ward, C., Bochner, S., \&Furnham, A. (2001). The Psychology of Culture Shock ( $2^{\text {nd }}$ Ed.). London: Routledge. 